\title{
Human Immunodeficiency Virus Infection in Young Adults: Treatment of Substance Use Disorders as a Priority Component of HIV Prevention, Care and Treatment in Low and Middle Income Countries
}

Review Article

Kresina TF*, Kaplowitz L, Johnson K

Center for Substance Abuse Treatment, Substance Abuse and Mental Health Services Administration, Rockville, MD USA.

Abstract

Young adults comprise roughly one-quarter of the global population and are at the developmental stage where personal life goals are formulated and personal independence is obtained. It is also the time of sexual debut and exposure to illicit drug and alcohol use. Thus, young adulthood is a time of high-risk for HIV transmission due to drug and alcohol use in the context of sexual activity. Social-networking, gender norms, economic, educational, familial, personal identity and development factors, among others, play a role in illicit drug and alcohol use and HIV infection in young adults. It is estimated that young adults account for $42 \%$ of new HIV infections globally, and that 4 million young adults living with HIV reside in sub-Saharan Africa. In Central Asia, Eastern Europe and the United States key populations are important subpopulations of young adults at high-risk for living with HIV. Subpopulations of young adults, particularly key populations, consume illicit drugs and alcohol with high-risk sexual and injection activity, thereby establishing connections between substance use/injection drug use/substance use disorders and HIV infection. Globally, interventions that comprise evidence-based prevention, care and treatment of substance use disorders targeting young adults and prioritizing treatment of substance use disorders as part of HIV care and treatment are vital to reduce the transmission of HIV infection and promote good clinical outcomes for young adults at-risk for and living with HIV.

Keywords: Young adults; Drug Use; Substance Use Disorder Treatment; HIV Infection; Alcohol Use.

\section{Introduction to Substance Abuse and HIV Infec- tion Among Young Adults}

The time span determining young adulthood is imprecise and is a function of psychosocial development and physical development which varies region to region and culture to culture. Studies have identified the age range to be between 16-40 years of age for young adulthood [1-3]. For the purpose of addressing substance use and substance use disorders in the context of Human Immunodeficiency Virus (HIV) infection during young adulthood, the age range of 16-30 years has been selected to reflect a time when life goals are formulated, along with meeting the challenges of independently facing a diverse, global and rapidly changing environment. This time frame, based on social norms, is the period of sexual debut (average age of first sex in 44 countries is 18.4 years) [4] and the consequences of first exposure to legal drugs, such as alcohol [5]. Globally, the median age for the initiation of alcohol use has been reported at 16-19 years of age, with nearly half of those initiating between the ages of 14-21 [5]. Exposure to alcohol in childhood or early adolescence and binge drinking in late adolescence confer an increased venerability to alcohol dependence as young adults $[6,7]$. National surveys, globally, show that approximately $70 \%$ of young adults consume alcohol and research studies show that young adults drink the most in their late teens to mid-twenties [8-11]. These data also show a gender component with more men being consumers of alcohol compared to women. Global burden of disease studies have shown that alcohol use disorders have been reported as the highest risk factor for disability adjusted life-years for young adults 20-24 years of age [12].

With regard to illicit drug use and young adults, prescription drug abuse is reported high in national surveys of developed countries with approximately $6 \%$ of young adults reporting non-medical

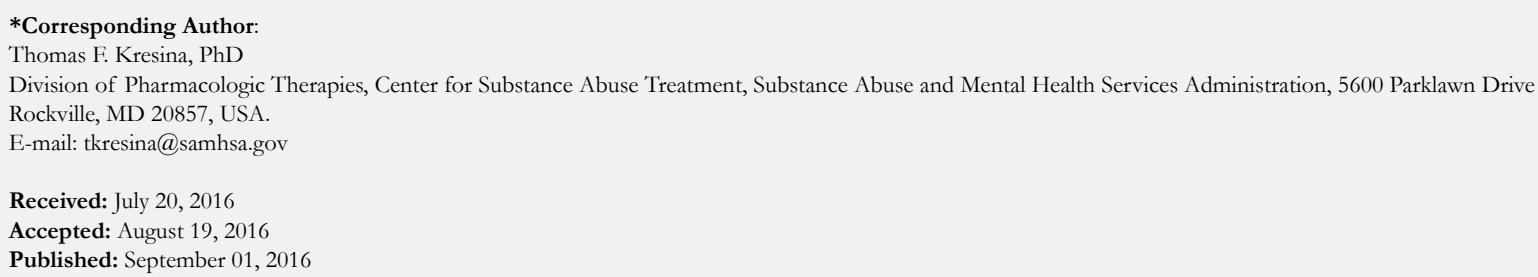

Citation: Kresina TF, Kaplowitz L, Johnson K (2016) Human Immunodeficiency Virus Infection in Young Adults: Treatment of Substance Use Disorders as a Priority Component of HIV Prevention, Care and Treatment in Low and Middle Income Countries. Int J AIDS Res. 3(7), 102-109. doi: http://dx.doi.org/10.19070/2379-1586-1600021

Copyright: Kresina TF $^{\circ}$ 2016. This is an open-access article distributed under the terms of the Creative Commons Attribution License, which permits unrestricted use, distribution and reproduction in any medium, provided the original author and source are credited. 
use of prescription drugs in the last month [13]. One in six urban young adults attending partying venues has been reported to combine illicit drug use with prescription drug abuse [14]. Of those abusing prescription drugs, $66 \%$ used the prescription drug with at least one illicit drug in common combination with marijuana, cocaine, ecstasy and psychotropic drugs. The misuse of over-the counter medications can also result in serious adverse medical events particularly when mixed with alcohol and other drugs [15]. Globally, young adults who misuse over-the-counter medications report a higher prevalence of hazardous alcohol use and illicit drug use [15-17]. Female sex workers and male clients in resource limited settings, who report over-the-counter or prescription drug abuse, are at higher risk for HIV infection through unsafe sex practices $[18,19]$. Illicit drugs most identified with an elevated risk of HIV transmission, either through injection drug practices or high-risk sexual behavior, are opioids, amphetamines and cocaine [20]. Globally, it has been reported that the median age of cocaine use is 21-24 years of age with nearly half initiating cocaine use between 19-28 years of age [5]. An estimate of global use of these illicit drugs can be found in the World Drug Report where it is reported that between 3.5 and $7.0 \%$ of the global population (ages 15-64) has used an illicit drug in the previous year [21]. It is also estimated that $10 \%$ of these individuals exhibit symptoms of a substance use disorder, indicating an uncontrolled use and abuse of the illicit drug. These latter individuals are at highest risk for either injection or sexual behaviors that place the illicit drug user at elevated risk for HIV transmission. Thus for young adults, data from global studies and national surveys show a convergence of the consequences of the initiation of drug and alcohol use along with a time of sexual debut, linking the young adult period with an elevated risk of HIV infection.

\section{Etiology of HIV Prevalence and Substance Abuse Prior to Young Adulthood}

While young adulthood is a time of high-risk for the transmission of HIV due to drug and alcohol use in the context of sexual activity, the prevalence of HIV infection in young adults comprises both infection prior to and during young adulthood. Prior to young adulthood, HIV infection can result from mother to child transmission (MTCT) or infection during adolescents due to high-risk activities. For MTCT, numerous studies [22-25] have documented that maternal use of cocaine and other illicit drugs results in a greater than three-fold higher risk for vertical transmission of HIV. This increased risk of transmission is evident for drug-using pregnant women who do not receive antiretroviral therapy during pregnancy to reduce the risk of perinatal vertical transmission [26]. Infants born with HIV infection have an excellent survival rate when provided anti-retroviral treatment under WHO treatment guidelines [27]. However, infants born with HIV infection have more factors associated with failure to thrive, and as they progress through childhood, adolescence and young adulthood experience poorer health and lower quality of life $[28,29]$. These individuals, living with HIV, as they progress to young adulthood, have a higher risk of prescription drug abuse, as well as, illicit drug and alcohol use due to both increase chronic health issues, as well as, the stigma and discrimination of growing up with HIV infection [30]. In addition, research has shown a genetic component to addiction where allelic phenotypes of genes related to both the brain and nervous system contribute to the onset of problematic drug and alcohol use, particularly in young adulthood [31]. Thus, the perfect storm forms for those acquiring HIV perinatally, comprising neonatal exposure to drugs and alcohol combined with genetic risk, chronic health conditions early in life, and poor quality of life into young adulthood, a time of onset for abuse of drugs and alcohol.

Another important risk factor for illicit drug and alcohol use, for individuals living with HIV as well as those without HIV, is growing up in a drug-using household [32]. Household and family substance use coupled with the stigma and discrimination of HIV infection provides a high-risk environment for the early initiation of illicit drug and alcohol use, along with sexual debut in adolescence or young adulthood. Growing up without the knowledge of HIV infection is also an issue. Young adults with perinatal HIV infection, who receive a late diagnosis of HIV infection in their teens or early twenties, face a life changing event during a time of developmental and emotional immaturity. Without significant support, these individuals are at-high risk for not only illicit drug and alcohol abuse and addiction, but also suicide and mental health disorders, such as major depression. Unfortunately, it is not uncommon in both resource rich and resource limited countries for young adults with perinatal HIV infection, and who receive limited health care services early in life, to be diagnosed with HIV infection in late adolescence or early young adulthood [33].

The early initiation of drug and/or alcohol use during adolescence, the developmental stage prior to young adulthood, is a high-risk behavior for the acquisition of HIV infection. The early initiation of drug and/or alcohol use in adolescence results in increased sexual risk-taking with the potential exposure to HIV infection [34]. So, what influences the early initiation of drug and/or alcohol use? Positive protective factors include a good adolescent-school relationship, as well as, good family- adolescent relationship which includes: positive parenting, parental involvement, family cohesion, family communication, parental monitoring of peers, and parent-adolescent communication [35]. Promotional factors for drug and alcohol use include those that foster the social acceptance of drug and alcohol use, such as household drug and/ or alcohol use, peer use of drugs and alcohol, the easy availability of alcohol and drugs, adolescent disengagement from school, poor family relationship(s) and poverty [5].

With regard to household drug/alcohol use, adolescents perinatally exposed to illicit drug use have a two fold increased risk in the use of drugs or alcohol by age 15 , as well as, an increased risk of early sexual debut $[36,37]$. In a low income setting, minority adolescents who were early initiators of sexual activity also reported substance use and illicit drug selling [38]. In this setting, youth who reported continuous involvement in drug use also reported intense sexual involvement, as compared to sexual experimentation. A highestrisk group for substance use and HIV transmission are homeless street youth. In both high income settings and low-income settings, street youth report daily use of alcohol and illicit drugs, as well as, high-risk sexual activities, including survival sex, that is, the engagement in sex work because of extreme need [39, 40]. The circumstance of social estrangement is a key factor in the lack of access and receipt of health services for substance use disorders and HIV infection [41]. Socially estranged adolescents are frequently involved with the criminal justice system and are a population that has been shown to have repeated sexually transmitted diseases [42]. Behaviors that place these youth at 
high-risk for HIV infection include binge-drinking, risky sexual encounters while intoxicated, intravenous drug use, and frequent incarceration [43-46]. A history of arrest and detention has been shown to be a marker for both adolescent HIV infection risk and substance abuse [47].

Since illegal behaviors have been shown to be a marker for substance abuse and HIV infection risk, behavior screening of adolescents and young adults is an important tool for health care providers. Adolescents and young adults, who are key at risk populations (people who inject drugs, men who have sex with men, sex workers and transgendered individuals), are confronted with laws and community practices that frequently criminalize their behaviors. This criminalization places them at high risk for HIV infection, sustained violence and discrimination for their behaviors, plus impeded access to drug and HIV-related prevention, care and treatment [48]. These individuals, along with homeless young adults, experience more unprotected sex, sexually transmitted infections, HIV infection, unintended pregnancies, violence, mental health disorders and substance use disorders than young adults in the general population [49]. The result is a marginalized population of young adults with the triple diagnosis of HIV infection, substance use disorder and mental health disorders who are estranged from needed medical care and treatment.

HIV infection is an epidemic among adolescent girls and young women in many parts of the world [50]. In Eastern and Southern Africa, young girls account for $80 \%$ of all new HIV infections and HIV/AIDS is the leading cause of death for girls aged 1519. The vulnerability to HIV results from gender inequality, lack of economic opportunity, intergenerational and transactional sex, stigma and discrimination due to sexual violence, forced marriage, trafficking and sex work. In Southwest Asia, roughly one-in-three trafficked women were determined to be living with HIV when provided health services [51]. Those trafficked into sex work have also been shown to be high consumers of drugs and alcohol [52]. Thus, for young women, the convergence of young age, sexual activity and drug or alcohol use presents a high-risk for HIVinfection and other social consequences [53].

\section{Prevalence of Substance Use/Substance Use Disorders and HIV Infection in Young Adults}

Currently, there are roughly 1.6 billion young people $12-24$ years of age and, thus, young adults represent roughly one-quarter of the global population [54, 55]. With regard to HIV infection, young people aged 15-24 account for $42 \%$ of new HIV infections and roughly 4 million of these young adults living with HIV live in sub-Saharan Africa [54]. AIDS is the number one cause of death for young adults in Africa. Young women in sub-Saharan Africa account for $58 \%$ of the young adults living with HIV [55]. Africa has one of the highest alcohol per capita consumption levels in young adults at 19.5 liters per person per year, as well as emerging regional drug abuse epidemics with heroin abuse along the coast in Eastern Africa, stimulant use in Southern and Western Africa $[56,57]$. Local situations vary with a high variability of multiples substances including local brews and spirts "gongo", as well as, cannabis "bhang" or other locally grown plants. Youths start using substances between the ages of 10 and 15 years and graduate to more potent substances as young adults [58].
In Central Asia and Eastern Europe, the HIV epidemic is driven by injection drug use and focused in key populations [59]. Recent studies have shown that young adults who were homeless were most likely to be living with HIV and injecting illicit drugs [60, 61]. Studies have shown that key populations who initiate drug use as young adults may have a 20 -fold risk for HIV infection and are less likely to seek HIV services [62]. In Central Asia and Eastern Europe, there are an estimated 3.7 million people who inject drugs, nearly one-quarters of the global total [63].

In the United States, young adults are the only age group to experience a rise in new HIV infection with nearly $40 \%$ of new infections occurring between the ages of 13-29 [64]. Men who have sex with men account for $72 \%$ of HIV infections in people under the age of 25. Also in the United States, there is a rapid onset of substance use disorders for young adults under the age of 20, with one-in-three young adults reporting lifetime alcohol use and $24 \%$ reporting illicit drug use- mostly marijuana or prescription drug abuse [65].

Elsewhere, in Asian countries, numerous studies have shown that for key populations the risk for HIV infection is substantial, but becomes even greater with alcohol or injection drug use [66-69]. In South America, cocaine is the drug of choice. Studies have shown young adult crack cocaine users experience health and economic marginalization, an elevated risk for HIV infection and compromised health along with poor health services utilization [70-72]. In the Dominican Republic, a recent study has addressed alcohol use in young adults in the context of risk for HIV infection [73]. This study notes that $18 \%$ of AIDS cases occur in young adults between the ages of $15-24$, with $29 \%$ of young adults reporting sexual debut before the age of 15 . These sexually active young adults are drug and alcohol experienced with one-inthree reporting binge drinking prior to the age of 12 . Hazardous chronic alcohol use is common with $25 \%$ of girls and $35 \%$ of boys reporting heavy episodic drinking.

Thus from Europe, Asia, Africa and the Americas-globally-the prevalence of substance use/substance use disorders and HIV infection in young adults is elevated and can be characterized as a heavy health burden. The relationship between substance use disorders and HIV infection is bidirectional and multifaceted with multiple components. The bidirectional nature of the relationship is the sequential exposure to either the HIV virus or illicit drugs or alcohol. The common direction is initial exposure to illicit drugs and alcohol followed by exposure to the HIV virus through high-risk sexual encounters or high-risk injection drug practices. Alternatively, young adults who acquire HIV infection through vertical transmission can initiate illicit drug or alcohol use early in life in adolescence or as young adults. In addition, in a less common scenario, young adults could be exposed to both the HIV virus and illicit drugs or alcohol in utero during pregnancy by women living with HIV who are using/addicted to drugs or alcohol during the pregnancy. The components of the relationship between substance use/substance use disorders and HIV infection in young adults comprise social, economic, familial, educational, legal, and human rights issues. These issues describe the young adult subpopulations (see Table 1) and risk factors as noted above in the etiology of exposure to the HIV virus and illicit drugs and alcohol. Regardless of the timing of the exposure to illicit drugs and alcohol, young adults who have hazardous levels of consumption or who are dependent on illicit drugs or alcohol, 
Table 1. Subpopulations of Young Adults and the Etiology of Substance Abuse and HIV Infection.

\begin{tabular}{|c|c|}
\hline Young Adult Subpopulation & Etiology \\
\hline Living with HIV through vertical transmission & $\begin{array}{c}\text { Material use of cocaine and other illicit drugs Risk for prescription drug } \\
\text { abuse/ street drugs/alcohol use as young adult }\end{array}$ \\
\hline Recent diagnosis of HIV infection in adolescence & Risk of drug or alcohol use and suicide \\
\hline Living in a drug or alcohol using household & Early initiation of drug/alcohol use or dependence \\
\hline High-risk sexual encounters & Initiation of drug/alcohol use as adolescent \\
\hline Homeless street youth/ young adult & Daily alcohol/drug use and survival sex \\
\hline Criminal justice involved youth/young adults & Marker for drug abuse and HIV infection \\
\hline Key Populations & High risk for HIV infection and drug/alcohol use or dependence \\
\hline Young women- trafficked sex workers & Drug/alcohol use as part of sex work, as well as unsafe sex practices \\
\hline Young women-sexual violence, forced marriage & Drug/alcohol use as self-medication of trauma \\
\hline
\end{tabular}

need to seek medical care through comprehensive substance abuse treatment programs. The importance and prioritization of seeking and receiving substance use disorder treatment cannot be over stated. Recent studies have shown that people who inject drugs that are in care or treatment are more likely to receive HIV testing and people living with HIV are more likely to have reduced survival due to drug or alcohol use $[74,75]$.

\section{Prioritizing Comprehensive Substance Abuse Treatment Programs Targeting Young Adults to Impact Global Health}

Young adults should routinely seek medical care from health care providers who are familiar with and have experience in providing primary care to individuals through their developmental stage(s) in life. In seeking care and treatment for substance use/substance use disorders in young adulthood, health care providers who are familiar with the stages of substance use progression and patterns of adolescent drug and alcohol use can provide evidence-based interventions, such as screening and brief interventions, to reduce hazardous levels of consumption [76]. Based on the level of abuse, an individual treatment plan should be developed as part of the assessment and intake process [77]. If the young adult is not ready for treatment, then the healthcare provider, even in a resource limiting setting, can engage the young adult with motivational interviewing techniques with the goal of reducing consumption levels of alcohol and other drugs [78, 79]. For young adults seeking or entering treatment, comprehensive treatment programs that provide services beyond treatment of the substance use disorder are effective evidence-based programs [80-82]. These programs address the health needs of the young adults and through case management and other interventions, as well as addressing family issues and support, educational, legal/ criminal justice and economic issues, including the stigma and discrimination associated with addiction. These programs also provide peer recovery support for the young adults as part of the reintegration effort with social change [83]. For people living with HIV in low and middle income countries, the integration of treatment for substance use disorders with HIV primary care is critical since screening, diagnosis and management of substance use disorders has high impact in achieving good HIV clinical outcomes $[84,85]$.

The effective treatment for substance use disorders for young adults living with HIV is important since access and adherence to anti-retroviral medication regimens leads to a normal and productive life span, as well as, dramatically decreasing the risk of HIV transmission. Substance use disorders interrupt normal life progression through biological changes in the immune system, increased poor nutrition and health, changes in socio-economic status, increased drug-related mortality, reduced access and uptake of medical care, as well as, poor adherence to medication regimens [86-89]. Treatment of substance use disorders in young adults, in addition to relapse prevention interventions and recovery support services reduces the number of young adults lost to follow-up in HIV care and treatment, as well as, a reduction in HIV transmission [84, 85, 90-92].

\section{The Challenges in Treatment of Substance Use Disorders and HIV Infection in Young Adults}

Numerous studies have identified the substantial challenges, particularly in low and middle income countries, in accessing and retaining adults living with HIV in HIV care and treatment [93-95]. These studies have identified patient, clinical and societal challenges that include: remote clinic locations, lack of transportation, fear of disclosing status, stigma, long clinic wait times, clinic staff shortages, fear of drug side effects, need to take time off from work and poverty. These challenges result in a cycling of adults in and out of care, particularly for men and young adults. Interventions to promote retention through the clinical care cascade comprise: 1) health system interventions, such as integration of services; decentralization, task-shifting, use of technology; 2) patient convenience and accessibility, such as point of care services, home based care and treatment, case management, use of first line medications; 3) behavioral interventions and peer support, such as patient referral and education, patient navigators, improved communication; and 4) incentives, such as food support or cash incentives [93, 95].

Focusing on young adults with substance use disorders, three additional challenges can be identified: (a) transitioning from adolescent care to adult care for those individuals who are living with HIV prior to reaching young adulthood and who were in care, (b) accessing HIV care and treatment from HIV testing with the dual comorbidities of substance use disorder and HIV infection and (c) out-of-care young adults disengaged from medical care. For all of these challenges, providing a young adult friendly venue 
that integrates comprehensive services for treatment of substance use disorder and HIV care and treatment provides the optimal opportunity for engagement and retention in care with good clinical outcomes [96].

For transitioning youth into adult HIV care, optimal care includes a formal plan for the transition from pediatrics/adolescent/ family care to adult care, as well as, a formal written policy on transfer $[97,98]$. The plan should be individualized for each youth based on specific developmental milestones addressing cognitive development, mental health, medication adherence, sexuality, reproductive and gender issues, stigma and discrimination, peer support, socioeconomic status and payment for services. A recent study [99] pilot tested a formal transfer protocol to assist the transition to adult care. Using the "Movin Out" transitioning protocol approximately half the youth were able to transition to adult care. Reasons for not transitioning were relocation, attrition, lost to follow-up and transfer to another service. Interestingly, substance abusing youth were successful in transitioning to adult care using this protocol [99].

For young adults with substance use disorders and diagnosed with HIV infection, accessing HIV care and treatment can be challenging. These individuals can face health system challenges, as well as, social and individual challenges [100,101]. These challenges include stigma, long waits for services, patient provider relationships, system navigation for health services and social services, and lack of family and peer support. Overcoming these barrier to HIV care are critical since patients in HIV treatment that also are retained in care report better treatment outcomes [101]. Interventions that promote linkage to HIV care and treatment include utilizing care coordinators to promote linkage and utilization of care, providing information and education on HIV care, providing motivational counseling, utilizing care navigators, providing coordinated services with good patientprovider communication along with social services [100-102].

For young adults with substance use disorders who are out of care, the priority is to initiate the Test and Treat algorithm [103]. Thus, in outreach efforts to these key populations, testing for HIV infection with concomitant rapid initiation of care and treatment is paramount. Studies have shown community-based HIV testing with facilitated linkage to care and treatment results in improved access to care and initiation of anti-retroviral treatment [104]. Home-based testing, mobile testing and self-testing were found to be accepted and facilitated access to care and entry into treatment for young adults $[104,105]$. Subsequent to the initiation of HIV care and treatment, young adults can be further stabilized with entry into comprehensive substance abuse treatment. Thus, interventions have been identified that successfully address the challenges encountered by young adults with substance use disorders in accessing and receiving HIV care and treatment.

\section{Recommendations}

Because of the association between substance use disorders and HIV infection, the overarching recommendation is to leverage the large global effort to control the HIV epidemic and further address the growing epidemic of substance use disorders in young adults. While there are substantial efforts in the global programs to address HIV related injection drug use, a greater effort is needed to address the early use of drugs and alcohol in young adults and adolescents. Substance use disorders can be addressed through global, national, regional and local prevention, care and treatment programs. Substance use prevention, care and treatment programs impacting young adults need to be targeted to developmental stages, started at preadolescence, and continued through adolescent stages. Such programs need to reinforce protective factors that promote abstinence for illicit drug and alcohol use, as well as provide resiliency for those young adults exposed and dependent on illicit drugs and alcohol. Effective, evidence-based treatment programs are needed that target the developmental stages of young adults including gender-based, key population focused and trauma-informed care and treatment, as part of the comprehensive package of services [106-108]. Salient specific recommendations are presented in Table 2.

Table 2. Salient recommendations addressing substance use and substance use disorder treatment in young adults living with HIV.

\section{Prevention and Awareness}

- Integrate drug and alcohol prevention components into global and national HIV awareness campaigns

- Develop educational materials on the linkage between HIV infection and drugs and alcohol targeted to

young adults young adult

- Develop national drug and alcohol strategies and action plans and address informal and formal alcohol

production, access and distribution

- Develop and promote community recovery activities and events

- Develop young adult social networking tools related to prevention of drug and alcohol use

- Integrate screening and brief interventions for drug and alcohol use in prenatal HIV programs

- Integrate HIV prevention efforts into drug and alcohol treatment programs Care and Treatment

- Implement, evaluation and scale-up effective evidence based comprehensive substance abuse treatment for young adults

- Integrate substance use disorder treatment into HIV care and treatment programs

- Promote gender-based treatment programs, key population focused programs and trauma-informed care

for violence-experienced individuals

- Promote the formation of recovery oriented systems of care and peer-based recovery programs

- Develop drug court programs for young adults to reduce incarceration of young adults for drug /alcohol

dependence

- Train public safety officers on drug /alcohol dependence as a health disorder; train on the use of overdose prevention medications 


\section{Conclusion}

The prevalence of substance use and substance use disorders in young adults living with and at high risk for HIV is high with the need to prioritize access to and retention in treatment for substance use disorders as part of HIV prevention, care and treatment in low and middle income countries. Leveraging the global effort to reduce HIV epidemic to provide programming for young adults living with and high risk for HIV and who use and abuse illicit drugs and alcohol will significantly impact the ability to reach the global goal of controlling the HIV epidemic.

\section{References}

[1]. Heffer CL. Erikson's Stages of Psychosocial Development. In Allpsych Psychol 101.2001:

[2]. Michaud PA, Ambresin AE (2014) The health of adolescents around the world in transition. Georgian Medl News, 230(5): 54-59.

[3]. Young Adult Development Project. The MIT Work Life Center (2008).

[4]. Charts Bin statistics collector team ( 2009), Average Age at First Sex by Country, ChartsBin.com.

[5]. Degenhardt L, Stockings E, Patton G, Hall WD, Lynskey M (2016) The increasing global health priority of substance use in young people. Lancet Psychiatry. 3(3): 251-64. doi: 10.1016/S2215-0366(15)00508-8.

[6]. Fergusson DM, Lynskey MT, Horwood LJ (1994) Childhood exposure to alcohol and adolescent drinking patterns. 89(8):1007-1016. DOI: 10.1111/j.1360-0443.1994.tb03360.x

[7]. Spear LP. (2015) Adolescent alcohol exposure: are there separate venerable periods with adolescence?. S0031-9384(15)00041-4. Doi:10.1016/j.physbeh.2015.01.027.

[8]. National Institute on Alcohol Abuse and Alcoholism (2006) Young Adult Drinking. Alcohol Alert.

[9]. Naimi TS, Brewer RD, Mokdad A. et al., (2003) Binge drinking among U.S. adults. JAMA 289(1):70-5.

[10]. Fillmore KM, Hartka E, Johnstone BM, et al., (1991) A meta-analysis of life course variation in drinking. Brit J Addict 86:1221-1268. DOI: 10.1111/ j.1360-0443.1991.tb01702.x

[11]. World Health Organization (2010) Global strategy to reduce the harmful use of alcohol.

[12]. Mokdad AH, Forouzanfar AH, Daoud F, et al., (2013) Global burden of disease s, injuries and risk factors for young people's health during 1990-2013: A systematic analysis for the Global Burden of Disease Study p2383-2401.

[13]. National Institute on Drug Abuse (2014) Prescription drug abuse. Adolescents and young adults.

[14]. Kelly BC, Wells BE, Pawson M, et al., (2014) Combinations of prescription drug misuse and illicit drugs among young adults. Addict Behav. 39(5): 941-944.

[15]. Benotsch EG, Koester S, Martin AM, et al., (2014) Intentional misuse of over-the-counter medications, mental health, and polysubstance use in young adults. J Community Health 39(4): 688-695. doi: 10.1007/s10900013-9811-9.

[16]. Myers B, Siegfried N, Parry CD (2003) Over-the-counter and prescription medicine misuse in Cape Town-findings from specialist treatment centres. $S$ Afr Med J. 93(5): 367-370

[17]. Dada S, Harker Burnhams N, Van Hout MC, Parry CD (2015) Codeine misuse and dependence in South Africa-learning from substance abuse treatment admissions. S Afr Med J 105(9): 776-779.

[18]. Carney T, Petersen Williams PM, Pluddemann A, Parry CD (2015) Sexual HIV risk among substance-using female commercial sex workers in Durban, South Africa. Afr J AIDS Res 14(2) 153-158. doi: 10.2989/16085906.2015.1040811

[19]. Datta D, Pandey S, Dutta S, Verma Y, Chakrabarti A (2015) Descriptive epidemiology and high risk behavior of male prescription opioid abusers: cross-sectional study from Sikkim, North East India. Indian J Psychiatry 57(3) 284-289. doi: 10.4103/0019-5545.166631.

[20]. Degenhardt L, Hall W, Warner-Smith M, Lynskey M. Illicit drug use (2004) In Comparative Quantification of Health Risks Chapter 13 pp 1109-1177.

[21]. United Nations Office on Drugs and Crime, World Drug Report (2014) United Nations publication, Sales No. E.14.XI.7.

[22]. Rodriquez EM, Mofenson LM, Chang BH, et al., (1996) Association of maternal drug use during pregnancy with maternal HIV culture positivity and perinatal HIV transmission. JAIDS 10(3): 273-282.
[23]. Matheson PB, Schoenbaum E, Greenberg B, Pliner V (1997) Association of maternal drug use during pregnancy with mother-to-child HIV transmission. New York City Perinatal HIV Transmission Collaborative Study. AIDS. 11(7): 941- 942

[24]. Cibulka NJ (2006) Mother-to-child transmission of HIV in the United States. Many HIV-infected women are now planning to have children. What are the risks to mother and infant? Am J Nursing. 106 (7):56-63.

[25]. Cook JA (2011) Associations between use of crack cocaine and HIV-1 disease progression: research findings and implications for mother-to-infant transmission. Life Sci 88(21-22):931-939.

[26]. Mofenson LM (2004) Successes and challenges in the perinatal HIV-1 epidemic in the United States as illustrated by the HIV-1 Serosurvey of childbearing women. 158(5):422-425.

[27]. Bertagnolio S, Penazzato M, Jordan MR, et al., (2012) World Health Organization generic protocol to assess drug-resistant HIV among children $<18$ months of age and newly diagnosed with HIV in resource-limited countries. 54 Suppl 4:S254-260. doi: 10.1093/cid/cis003.

[28]. Miller TL, Easley KA, Zhang W, et al., (2001) Maternal and infant factors associated with failure to thrive in children with vertically transmitted human immunodeficiency virus-1 infection: the prospective, P2C2 human immunodeficiency virus multicenter study. Pediatrics. 108(6):1287-1296.

[29]. Bunupuradah T, Kosalaraksa P, Vibol U, et al., (2013) Impact of antiretroviral therapy on quality of life in HIV-infected Southeast Asian children in the PREDICT study AIDS Patient Care STDS. 27(11):596-603. doi: 10.1089/apc.2013.0203.

[30]. Korthuis PT, Zephyrin LC, Fleishman JA, et al., (2008) Health-related quality of life in HIV-infected patients: the role of substance use. AIDS Patient Care STDS. 22(11):859-867. doi: 10.1089/apc.2008.0005.

[31]. Edwards AC, Aliev F, Wolen AR, et al., (2015) Genomic influences on alcohol problems in a population-based sample of young adults. Addiction 110 (3): 461-470.

[32]. Frank DA, Kuranz S, Appugliese D, et al. (2014) Problematic substance use in urban adolescents: role of intrauterine exposures to cocaine and marijuana and post-natal environment. Drug Alcohol Depend. 142: 181-190. doi: 10.1016/j.drugalcdep.2014.06.014.

[33]. Judd A, Ferrand RA, Jungmann E, et al., (2009) Vertically acquired HIV diagnosed in adolescence and early adulthood in the United Kingdom and Ireland: findings from national surveillance. HIV Medicine. 10(4):253-256. doi: 10.1111/j.1468-1293.2008.00676.x.

[34]. Sales JM, Brown JL, Vissman AT, DiClemente RJ. (2012) The association between alcohol use and sexual risk behaviors among African American women across three developmental periods: a review. Current Drug Abuse Rev. 5(2):117-128.

[35]. Cordova D, Huang S, Lally M, et al., (2014) Do parent-adolescent discrepancies in family functioning increase the risk of Hispanic adolescent HIV risk behaviors? Family Process 53(2):348-363. doi:10.1111/famp.12067.

[36]. Minnes S, Singer L, Min MO, et al. (2014) Effects of prenatal cocaine/polydrug exposure on substance use by age 15 Drug Alcohol Depend 134:201210. doi:10.1016/j.drugalcdep.2013.09.031.

[37]. DeGenna N, Goldschmidt L, Richardson GA. (2014) Prenatal cocaine exposure and age of sexual initiation: direct and indirect effects. Drug Alcohol Depend.145:194-200. doi: 10.1016/j.drugalcdep.2014.10.011.

[38]. Stanton B, Li X, Cottrell Kaljee L (2001) Early initiation of sex, drug-related risk behaviors, and sensation-seeking among urban, low-income AfricanAmerican adolescents. J Nat Med Assoc 93(4):129-138.

[39]. Oppong Asante K, Meyer-Waitz A, Petersen I (2014) Substance use and risky sexual behaviors among street connected children and youth in Accra, Ghana. Subst Abuse Treat Prevent Policy 9:45-54.

[40]. Cheng T, Wood E, Nguyen P, et al., (2014) Increases and decreases in drug us attributed to housing status among street-involved youth in a Canadian Setting. Harm Reduct J 11:12-18.

[41]. Krug A, Hildebrand M, Sun N. (2015) "We don't need services. We have no problems": exploring the experiences of young people who inject drugs in accessing harm reduction services. 26:18(2 Suppl1):19442. doi: 10.7448/ IAS.18.2.19442.

[42]. Pagano ME, Maietti CM, Levine AD.(2014) Risk factors of repeated infectious disease incidence among substance-dependent girls and boys courtreferred to treatment. 41(3):230-6. doi:10.3109/00952990.2014.939753.

[43]. Baljunas D, Rehm J, Irving H, Shuper P (2010) Alcohol consumption and risk of incident human immunodeficiency virus infection: a meta analysis. 55(3):159-66. doi: 10.1007/s00038-009-0095-x.

[44]. Molitor F, Truax SR, Ruiz JD, Sun RK. (1998) Association of methamphetamine use during sex with risky sexual behaviors and HIV infection among non-injection drug users. West J Med 168:93-97.

[45]. Miller JW, Naimi TS, Brewer RD, Jones SE (2007) Binge drinking and associated health risks behaviors among high school students. Pediatrics 119:76-85 
[46]. Bjekic M, Vlajinac H, Marinkovic J (1996) Behavioral and social characteristics of subjects with repeated sexually transmitted diseases. J Adolesc Health 18: 270-275.

[47]. Tolou-Shams M, Brown LK, Gordon G, et al., (2007) Arrest history as an indicator of adolescent/adult substance use and HIV risk. Drug Alcohol Depend 88: 87-90.

[48]. El Feki S, Avafia T, Fidalgo TM, et al., (2014) The Global Commission on HIV and the Law: recommendations for legal reform to promote sexual and reproductive health and rights. 22(44):125-36. doi: 10.1016/S09688080(14)44807-9.

[49]. Delany-Moretlwe S, Cowan FM, Busza J, et al., (2015) Providing comprehensive health services for young key populations: needs, barriers and gaps. J Internat AIDS Soc. 18(2 Suppl 1):19833. doi: 10.7448/IAS.18.2.19833. eCollection 2015.

[50]. Fleischman J, Peck K (2015) Addressing HIV risk in Adolescent Girls and young women. A Report of the CSIS Global health Policy Center. Center for Strategic \& International Studies, Washington, DC.

[51]. Oram S, Stöckl H, Busza J, et al., (2012) Prevalence and risk of violence and the physical, mental, and sexual health problems associated with human trafficking: systematic review. 9(5):e1001224. doi: 10.1371/journal. pmed.1001224. Epub 2012 May 29.

[52]. Silverman JG, Raj A, Cheng DM, et al., (2011) Sex trafficking and initiation-related violence, alcohol use, and HIV risk among HIV-infected female sex workers in Mumbai, India. J Infect Dis 204 Suppl 5:S1229-34. doi: 10.1093/infdis/jir540.

[53]. Li X, Stanton B, Cottrell L, et al. (2001) Patterns of initiation of sex and drug-related activities among urban low-income African-American adolescents. J Adolesc Health. 28(1):46-54.

[54]. UNAIDS FACT SHEET. Adolescents, young people and HIV. (2012). 20120417_adolescentsyoungpeopleandhiv_en.pdf

[55]. Idele P, Gillespie A, Porth T, et al. (2014) Epidemiology of HIV and AIDS among adolescents: current status, inequities, and data gaps. JAIDS 66 Suppl 2:S144-53. doi:10.1097/QAI.0000000000000176.

[56]. World Health Organization WHO. Global status report on alcohol and health (2014)

[57]. Bulletin of the World Health Organization. The Health of People: What Works. Chapter 5 Health Determinants.

[58]. Fact Sheet. African Medical and Research Foundation (AMREF) Bunda.

[59]. DeHovitz J, Uuskula A, El-Bassel (2014) The HIV epidemic in Eastern Europe and Central Asia. Curr HIV/AIDS Rep. 11:168-176

[60]. Jolley E, Rhodes T, Platt L, et al., (2012) HIV among people who inject drugs in Central and Eastern Europe and Central Asia: a systematic review with implications for policy. 2(5). pii: e001465. doi: 10.1136/bmjopen-2012-001465.

[61]. Hillis SD, Zapata L, Robbins CL, et al., (2012) HIV seroprevalence among orphaned and homeless youth: no place like home. AIDS. 26(1):105-10. doi: 10.1097/QAD.0b013e32834c4be4.

[62]. Grosso AL, Ketende S, Dam K, et al., (2015) Structural determinants of health among women who started selling sex as minors in Burkina Faso. JAIDS 68 Suppl 2:S162-70. doi: 10.1097/QAI.0000000000000447.

[63]. UNICEF. Blame and Banishment: The underground HIV epidemic affecting children in Eastern Europe and Central Asia. (2010). ISBN 9789280645460

[64]. amFAR: National Youth HIV/AIDS awareness day (2015).

[65]. FACT Sheet: Substance use, HIV, and youth: Tips for HIV clinicians. (2014) Pacific Southwest Addiction Technology Transfer Center, Drew University AETC, Addiction Technology Transfer Centers, Pacific AIDS Education and Training Center.

[66]. Kermode M, Sono CZ, Songput CH, Devine A (2013) Falling through the cracks: a qualitative study of HIV risks among women who use drugs and alcohol in Northeast India. BMC Intern Health Hum Rights. 13: 9. doi: 10.1186/1472-698X-13-9.

[67]. Xu J, Smith MK, Ding G, et al., (2013) Drug use and sex work: competing risk factors for newly acquired HIV in Yunnan, China. PLoS One. 8(3):e59050. doi: 10.1371/journal.pone.0059050.

[68]. Tran BX, Nguyen TV, Pham QD, et al., (2014) HIV infection, risk factors, and preventive services utilization among female sex workers in the Mekong Delta Region of Vietnam. PLoS One. 24; 9(1): e86267. doi: 10.1371/journal.pone.0086267.

[69]. Wu CS, Wong HT, Shek CH, Loke AY (2014) Multi-dimensional self-esteem and substance use among Chinese adolescents. Subst Abuse Treat Prev Policy. 9: 42. doi: 10.1186/1747-597X-9-42.

[70]. Santos Cruz M, Andrade T, Bastos FI, et al., (2013) Key drug use, health and socio-economic characteristics of young crack users in two Brazilian cities. Intern J Drug Policy. 24(5):432-8. doi: 10.1016/j.drugpo.2013.03.012.

[71]. Bertoni N, Burnett C, Cruz MS, et al., (2014) Exploring sex differences in drug use, health and service use characteristics among young urban crack users in Brazil. Intern J Equity Health. 13(1): 70. doi: 10.1186/s12939014-0070-x.

[72]. Santos Cruz M, Andrade T, Bastos FI, et al., (2013) Patterns, determinants and barriers of health and social service utilization among young urban crack users in Brazil. BMC Health Serv Res 13:536. doi: 10.1186/1472 6963-13-536.

[73]. Guilamo-Ramos V, Jaccard J, Lushin V, et al., (2011) HIV Risk Behavior among Youth in the Dominican Republic: The Role of Alcohol and Other Drugs. J Intern Assoc Phys AIDS Care (Chicago). 10(6):388-95. doi: $10.1177 / 1545109711419264$

[74]. Cooley LA, Wejnert C, Spiller MW, Broz D, Paz-Bailey G, NHBS study Group (2016) Low HIV testing among persons who inject drugs-National HIV Behavioral Surveillance, 20 U.S. cities, 2012 Drug Alcohol Depend. Jun 2. pii: S0376-8716(16)30141-7. doi: 10.1016/j.drugalcdep.2016.05.024.

[75]. Petoumenos K, Law MG (2016) Smoking, alcohol and illicit drug use effects on survival in HIV-positive persons. Curr Opin HIV AIDS. Jun 20.

[76]. Harris SK, Louis-Jacques J, Knight JR (2014) Screening and brief intervention for alcohol and other abuse. Adolesc Med State Art Rev. 25(1):126-56.

[77]. National Institutes of Drug Abuse. National Institutes of Health. Principles of drug addiction treatment. A research based guide. (2000) NIH publication N0. 00-4180.

[78]. Mertens JR, Ward CL, Bresick GF, et al., (2014) Effectiveness of nursepractitioner-delivered brief motivational intervention for young adult alcohol and drug use in primary care in South Africa: a randomized clinical trial. Alcohol Alcohol. 49(4):430-8. doi: 10.1093/alcalc/agu030.

[79]. L Engle KL1, Mwarogo P, Kingola N, et al., (2014) A randomized controlled trial of a brief intervention to reduce alcohol use among female sex workers in Mombasa, Kenya. JAIDS. 1;67(4):446-53. doi: 10.1097/ QAI.0000000000000335.

[80]. Slesnick N, Guo X, Brakenhoff B, Bantchevska D (2015) A comparison of three interventions for homeless youth evidencing substance use disorders: Results of a randomized clinical trial. J Subst Abuse Treat. pii: S07405472(15)00040-9. doi: 10.1016/j.jsat.2015.02.001.

[81]. Henderson CE, Young DW, Jainchill N, et al., (2007) Program use of effective drug abuse treatment practices for juvenile offenders. J Subst Abuse Treat. 32(3):279-90.

[82]. Copello AG, Templeton L, Velleman R (2006) Family interventions for drug and alcohol misuse: is there a best practice? Curr Opin Psychiat. 19(3): 271-6.

[83]. Kelly JF, Stout RL, Greene MC, Slaymaker V (2014) Young adults, social networks, and addiction recovery: post treatment changes in social ties and their role as a mediator of 12-step participation. PLoS One. 9(6):e100121. doi: 10.1371/journal.pone.0100121. eCollection 2014

[84]. Kresina TF, Conder LD, Lapidos-Salaiz IF (2016) The Impact of Screening, Diagnosis and Management of Alcohol Use Disorders In HIV Care in Low and Middle Income Countries. Ann Pub Health Res 3(1): 1035.

[85]. Kresina TF, Condor LD, Lapidos-Salaiz IF. (2016) The Impact of Screening, Diagnosis and Management of Substance Use and Addictive Disorders In HIV Care in Low and Middle Income Countries. Res HIV Retroviral Infect 1. 1:1-10.

[86]. Schneider M, Chersich M, Temmerman M, et al., (2014) The impact of alcohol on HIV prevention and treatment for South Africans in primary healthcare. Curationis. 37(1): 1-8. doi: 10.4102/curationis.v37i1.1137.

[87]. Meade CS, Towe SL, Skalski LM, Robertson KR (2015) Independent effects of HIV infection and cocaine dependence on neurocognitive impairment in a community sample living in the southern United States. Drug Alcohol Depend. 149:128-35. doi: 10.1016/j.drugalcdep.2015.01.034.

[88]. Larney S, Bohnert AS, Ganoczy D, et al., (2015) Mortality among older adults with opioid use disorders in the Veteran's Health Administration, 2000-2011. Drug Alcohol Depend. 147: 32-7. doi: 10.1016/j.drugalcdep.2014.12.019.

[89]. Passaro RC, Pandhare J, Qian HZ, Dash C (2015) The Complex Interaction Between Methamphetamine Abuse and HIV-1 Pathogenesis. J Neuroimmune Pharmacol.

[90]. Pecoraro A1, Mimiaga M, O'Cleirigh C, et al., (2015) Depression, substance use, viral load, and CD4+ count among patients who continued or left antiretroviral therapy for HIV in St. Petersburg, Russian Federation. AIDS Care. 27(1): 86-92. doi: 10.1080/09540121.2014.959464.

[91]. Altice FL, Bruce RD, Lucas GM, et al. (2011) HIV treatment outcomes among HIV-infected, opioid-dependent patients receiving buprenorphine/ naloxone treatment within HIV clinical care settings: results from a multisite study. JAIDS 56 Suppl 1:S22-32. doi: 10.1097/QAI.0b013e318209751e.

[92]. Singh PM, Shrestha DM, Bhandari GP (2014) A qualitative assessment of methadone maintenance therapy program in Nepal: evidence to scaling up at national level. Nepal Med Coll J 16(1): 17-19.

[93]. Govindasamy D, Ford N, Kranzer K (2012) Risk factors, barriers and facilitators for linkage to antiretroviral therapy care: a systematic review. AIDS 
26(16): 2059-2067.

[94]. Kranzer K, Govindasamy D, Ford N, Johnson V, Lawn SD (2012) Quantifying and addressing loss along the continuum of care for people living with HIV infection in sub-Saharan Africa: a systematic review. J Int AIDS Soc 15(2):1783. doi: 10.7448/IAS.15.217383.

[95]. Govindasamy D, Meghi J, Kebede-Negussi E, Clare Baggaley R, Ford N, et al., (2014) Interventions to improve or facility linkage to or retention in pre-ART (HIV) care and initiation to ART in low and middle-income settings- a systematic review. J Int AIDS Soc. 17:19032. doi: 10.7448/ IAS.17.1.19032. eCollection 2014

[96]. Kresina TF, Lubran R, Clark HW, Cheever LW (2012) Mediation Assisted Treatment, HIV/AIDS and the Continuum of Response for People Who Inject Drugs. Article ID 541489.

[97]. Cervia JS. (2013) Easing the transition of HIV-infected adolescents to adult care. AIDS Patient Care STDs. 27(12): 692-696.

[98]. Fair CD, Sullivan K, Gatto A (2011) Indicators of transition success for youth living with HIV: perspectives of pediatric and adult infectious disease care providers. AIDS Care 23(8): 965-970.

[99]. Maturo D, Powell A, Major-Wilson H, Sanchez K, De Santis JP, et al., (2015) Transtioning adolescents and young adults with hIV infection into adult care: pilot testing the "Movin Out" transition protocol. J Pediatr Nurs.30(5): 29-35. Doi:10.1016/pedn.2015.06.013

[100]. Bauman LJ, Braunstein S, Calderon Y, Chhabra R, Cutler B, et al. (2013) Barriers and facilitators of linkage to HIV primary care in New York City. 64 (S1): s20-S26.

[101]. Remien RH, Bauman LJ, Mantell JE, Tsoi B, Lopez-Rios J, et al. (2015) Barriers and facilitators to engagement of vulnerable populations in HIV primary care in New York City. 69 (S1): s16-S24.

[102].Liau A, Crepaz N, Lyles CM, Higa DH, Mullins MM, et al., (2013) Interventions to promote linkage to and utilization of HIV medical care among HIV-diagnosed persons: a Qualitative systematic review, 1996-2011. AIDS Behav 17: 1941-1962.

[103].Lange JMA (2011) "Test and Treat": Is it enough. Clin Infect Dis 52(6) 801-802.

[104]. Sharma M, Ying R, Tarr G, Barnabas R (2015) Systematic review and metaanalysis of community and facility-based HIV testing to address linkage to care gaps in sub-Saharan Africa. Nature 528(7580): s-77-s85.

[105].Sabapathy K, Van den Bergh R, Fidler S, Hayes R, Ford N (2012) Uptake of home-based voluntary testing in sub-Saharan Africa: a systematic review and meta-analysis. PLoS Med 9(12): e1001351. Doi:10.1371/journal. pmed.1001351.

[106].Ashley OS, Marsden ME, Brady TM (2003) Effectiveness of substance abuse treatment programming for women: a review. Am J Drug Alcohol Abuse. 29(1):19-53.

[107]. Substance Abuse and Mental Health Services Administration (US) (2014) Trauma-Informed Care in Behavioral Health Services. SAMHSA/CSAT Treatment Improvement Protocols Number 57. Center for Substance Abuse Treatment (US). Rockville (MD): Report No.: (SMA) 14-4816.

[108].López-Castro T, Hu MC, Papini S, et al., (2015) Pathways to change: Use trajectories following trauma-informed treatment of women with co-occurring post-traumatic stress disorder and substance use disorders. Drug Alcohol Rev. Mar 4. doi: 10.1111/dar.12230. 